\title{
Impact of radiotherapy duration on overall survival in squamous cell carcinoma of the anus
}

\author{
Shahil Mehta ${ }^{1 \#}$, Stephen J. Ramey ${ }^{1,2 \#}$, Deukwoo Kwon ${ }^{3}$, Benjamin J. Rich ${ }^{1}$, Awad A. Ahmed ${ }^{1}$, \\ Aaron Wolfson ${ }^{1}$, Raphael Yechieli ${ }^{1}$, Lorraine Portelance ${ }^{1}$, Eric A. Mellon ${ }^{1}$ \\ ${ }^{1}$ Department of Radiation Oncology, Sylvester Comprehensive Cancer Center/University of Miami Miller School of Medicine, Miami, FL, USA; \\ ${ }^{2}$ Department of Radiation Oncology, Georgia Cancer Center, Augusta University, Augusta, GA, USA; ${ }^{3}$ Biostatistics and Bioinformatics Shared \\ Resource, Sylvester Comprehensive Cancer Center/University of Miami Miller School of Medicine, Miami, FL, USA \\ Contributions: (I) Conception and design: All authors; (II) Administrative support: None; (III) Provision of study materials or patients: S Mehta, \\ SJ Ramey; (IV) Collection and assembly of data: S Mehta, SJ Ramey, D Kwon; (V) Data analysis and interpretation: All authors; (VI) Manuscript \\ writing: All authors; (VII) Final approval of manuscript: All authors. \\ \#These authors contributed equally to this work. \\ Correspondence to: Stephen J. Ramey, MD. 821 St. Sebastian Way, HK-121, Augusta, Georgia 30912, USA. Email: stephenramey@gmail.com.
}

\begin{abstract}
Background: Prolongation of radiotherapy (RT) in the treatment of numerous types of cancer has been shown to reduce overall survival (OS). Treatment delays are common in squamous cell carcinoma of the anus (SCCA) due to the toxicity of definitive chemoradiation (CRT). The effect of these delays on outcomes has not been well evaluated. This study investigated the effects of RT prolongation on OS in patients receiving CRT for SCCA.
\end{abstract}

Methods: The National Cancer Database was queried for adult patients diagnosed with SCCA and treated with CRT from 2004-2014. Cox proportional hazard regression models examined the effect of duration of RT, measured as fractions delivered per week, on OS. Negative binomial regression assessed the effects of demographic and prognostic factors on the duration of RT.

Results: A total of 8,948 patients were included in the analysis of factors impacting treatment duration, and 6,429 patients in the OS analysis. Multivariable analysis (MVA) showed female gender, non-private insurance, treatment at a low or intermediate volume facility, Charlson/Deyo score $\geq 2$, and advanced disease were associated with longer RT duration. Treatment with IMRT, with single agent chemotherapy, at an academic center, and in later years were associated with shorter RT duration. A decrease in fractions delivered per week was independently associated with reduced OS with a cutoff of 4.72 fractions per week (about 2 missed fractions over a 30 fraction treatment) delineating the largest differences in OS.

Conclusions: Efforts should be made to avoid RT interruptions of any length in SCCA patients and to compensate for treatment breaks to reduce the total duration of RT.

Keywords: Anus neoplasms; carcinoma; squamous cell; chemoradiotherapy; radiotherapy; overall treatment time; National Cancer Database; treatment duration

Submitted Dec 11, 2019. Accepted for publication Feb 14, 2020.

doi: 10.21037/jgo.2020.02.09

View this article at: http://dx.doi.org/10.21037/jgo.2020.02.09

\section{Introduction}

In 2019 an estimated 8,300 patients will be diagnosed with anal cancer, and the disease is expected to result in 1,280 deaths (1). The incidence of squamous cell carcinoma of the anus (SCCA) has steadily increased, likely due to changing sexual practices resulting in increased prevalence of HPV (2-4). SCCA is the most common histology 
accounting for $80 \%$ of anal cancers (5). Chemoradiotherapy (CRT), consisting of radiotherapy (RT) and concurrent 5-fluorouracil and mitomycin-C, is the standard therapy for SCCA $(6,7)$. Outcomes for patients with localized SCCA treated with this regimen are favorable with 5-year progression-free survival of $79 \%$ (7).

The optimal RT duration, fractionation schedule, and dose have not been definitively established and vary based upon individual provider practice. National Comprehensive Cancer Network (NCCN) guidelines recommend a minimum dose of 45 Gy delivered in $1.8 \mathrm{~Gy}$ fractions resulting in 25 fractions delivered over 5 weeks (8). For T2-T4 lesions or node-positive disease these guidelines recommend a boost of 9-14 Gy, delivered in 1.8-2 Gy fractions, resulting in a total dose of 54-59 Gy delivered in 30-32 fractions over 6-7.5 weeks. Due to the toxicity of CRT, RT delays are common with toxicity-related breaks in $49-80 \%$ of patients $(6,9,10)$.

Although delays are common, the impact of delays on SCCA outcomes has not been well characterized. Limited evidence suggests that longer RT treatment gaps result in reduced local control (LC) (11-13) and diseasefree survival (DFS) (14). Other studies, however, show no differences in outcomes based on RT interruptions, including a pooled analysis of two Radiation Therapy Oncology Group (RTOG) studies (15-17). Many of these studies, however, did not utilize the current standard of care treatment or relied on a small sample size (11-17). In cancers of other primary anatomic sites, prolongation of RT has been well associated with reduced overall survival (OS) and LC (18). This has been found particularly in head and neck cancer (19-21) and cervical cancer (22,23), two malignancies that often share similar viral etiology (HPV) and histology (squamous cell carcinoma) to SCCA. These poorer outcomes associated with prolonged treatment may be caused by accelerated repopulation of tumor cells during treatment interruptions (18).

Given the limited and conflicting results of previous studies on the effect of RT prolongation on outcomes in SCCA, a more thorough analysis is justified. This study was designed to assess the impact of radiation treatment time on OS for patients with SCCA using the National Cancer Database (NCDB) and to evaluate possible demographic and prognostic characteristics associated with a prolonged duration of RT.

\section{Methods}

Since de-identified data was used in this analysis, it was declared exempt from Institutional Review Board oversight by the sponsoring institution. Data was obtained from the American College of Surgeons and consisted of the 2014 NCDB participant user file (PUF). The NCDB is a joint project between the Commission on Cancer (CoC) of the American College of Surgeons and the American Cancer Society. The database consists of 34 million cancer patient records consisting of approximately $70 \%$ of newly diagnosed cancer patients reported from approximately $30 \%$ of all US hospitals (24-26). The CoC's NCDB and the hospitals participating in the $\mathrm{CoC} \mathrm{NCDB}$ are the source of the de-identified data used here; they have not verified and are not responsible for the statistical validity of the analysis or the conclusions derived by the authors (24).

\section{Patient selection}

A total of 54,069 patients aged 18 or older diagnosed with anal cancer between 2004 and 2014 were initially identified. Exclusion criteria are displayed in Figure 1. Patients were excluded if they had in situ primary disease without nodal metastases or distant metastases. Only patients with International Classification of Diseases for Oncology, 3rd Edition (ICD-O-3) site codes for histology of SCCA and pathologic confirmation of disease were included (27). Included patients received concurrent CRT, defined as a maximum 7-day period between the initiation of chemotherapy and the initiation of RT. Patients who underwent salvage surgery were included if surgery followed initiation of RT by at least 89 days (33 days for a minimal time to complete 25 fractions plus 56 days for the minimum NCCN recommended time for follow-up digital rectal exam after RT) (8). Patients receiving non-standard RT modalities and patients receiving RT to non-pelvic sites were excluded.

Patients were included if RT duration was 33-100 days, if the number of RT fractions were 25-33 fractions, and the total RT dose was 45-60 Gy. The upper bound for elapsed days of RT was based on the standard CRT arm of RTOG 98-11 which allowed for a maximum of 100 days (6). The lower bound of 33 days is the minimum number of possible days for delivery of 5 fractions per week with weekend breaks on a 25 fraction schedule. Bounds for 


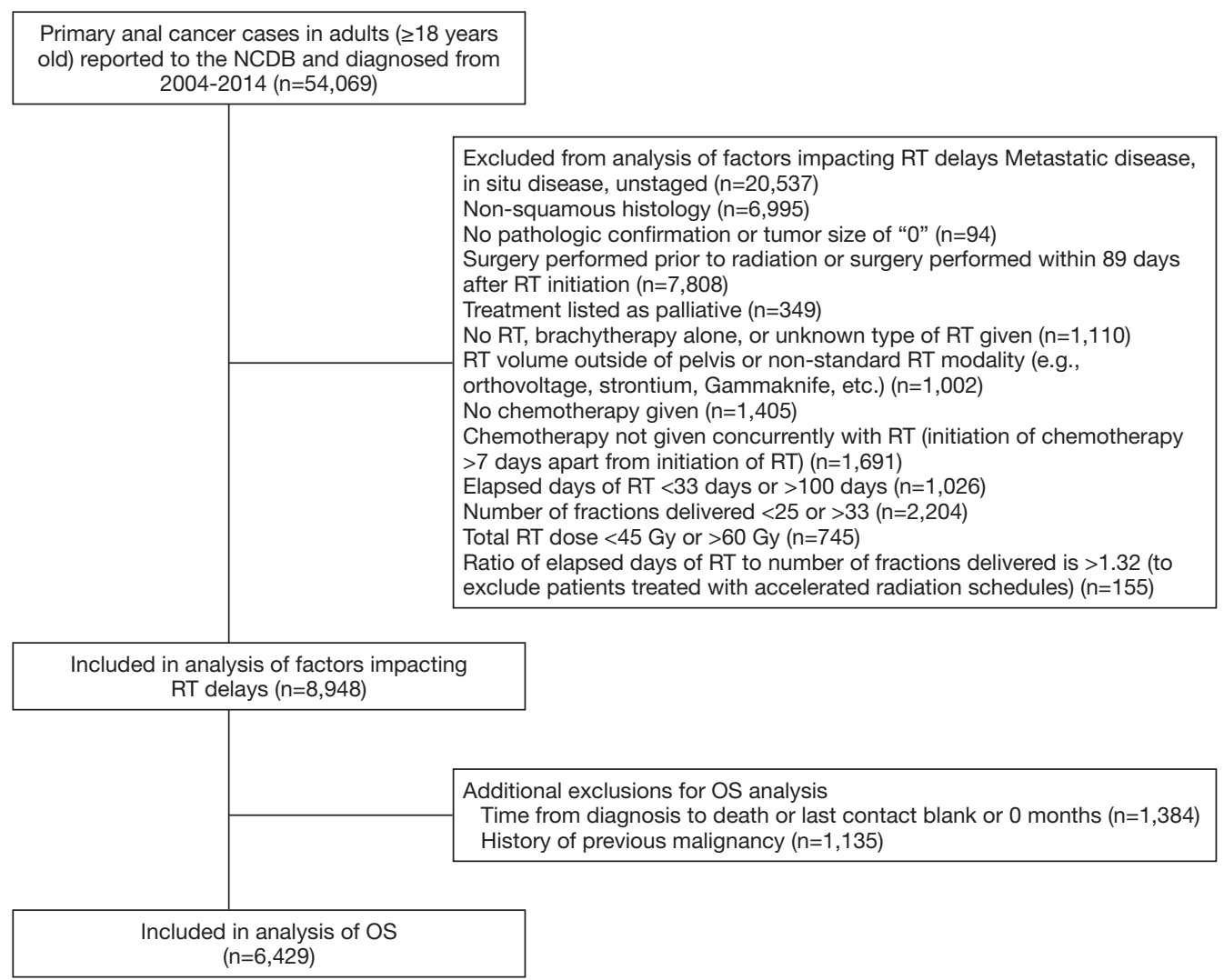

Figure 1 Exclusion criteria showing the number of patients excluded by each criterion. NCDB, National Cancer Database; OS, overall survival; RT, radiation therapy.

fraction number and total dose were determined by NCCN guidelines, except for the upper bound of total dose (8). The upper bound of 60 Gy was based on the standard arm of the ACCORD 03 trial to allow for variability beyond NCCN guidelines $(8,28)$. Finally, patients were excluded if they had a ratio of fractions to treatment days of more than 5.3 fractions per week (maximum possible RT treatment rate determined based on 25 fractions starting on a Monday including weekend breaks) to exclude accelerated fractionation regimens. Additional exclusion criteria for the OS analysis included patients with an unknown time from diagnosis to death or a time listed as ' 0 ' and patients with a prior malignancy (29).

\section{Statistical methods}

Multivariable analysis (MVA) assessed the impact of demographic, treatment, and prognostic factors on duration of RT, and utilized covariates listed in Table 1. The Charlson/Deyo comorbidity index is a weighted score derived from ICD-9 and ICD-10 secondary diagnosis codes. Scores are condensed by the NCDB to 0,1 , and 2 (with 2 representing all cases with a score $>1$ ). AJCC clinical stage and TNM classification were reported based on the edition in place at the time of diagnosis (29). Patients receiving proton therapy were grouped with patients receiving IMRT. Total duration of RT was calculated as the number of days between the date RT started and the date on which RT ended plus 1 day. For the OS analysis, duration of RT was normalized to fractions delivered per week (total duration of RT in days divided by 7) given the variation in treatment schedules (i.e., patients could have 25 to 33 planned fractions and would have inherent differences in treatment time). The estimated missed days of RT was based on the difference between total duration of RT and the maximum possible number of days the patient's fractionation schedule would require if it were started on a Friday (i.e., treatment for a 25 fraction regimen would take 35 days if started on a Friday and 33 days if started on a Monday therefore 35 days would be used in this calculation). This method 
Table 1 Patient demographic, treatment/treatment center, and prognostic characteristics within the RT duration cohort and the overall survival (OS) cohort

\begin{tabular}{|c|c|c|}
\hline Category & $\begin{array}{l}\text { RT duration cohort } \\
\text { number }(\%)\end{array}$ & $\begin{array}{c}\text { OS cohort } \\
\text { number (\%) }\end{array}$ \\
\hline Total & 8,948 (100.0) & 6,429 (100.0) \\
\hline \multicolumn{3}{|l|}{ Race/ethnicity } \\
\hline Non-Hispanic White & $7,253(81.1)$ & $5,179(80.6)$ \\
\hline Hispanic & $391(4.4)$ & $295(4.6)$ \\
\hline Non-Hispanic Black & $755(8.4)$ & $537(8.4)$ \\
\hline AAPI & $88(1.0)$ & $68(1.1)$ \\
\hline Other/unknown & $461(5.2)$ & $350(5.4)$ \\
\hline \multicolumn{3}{|l|}{ Gender } \\
\hline Male & 2,617 (29.2) & $1,928(30.0)$ \\
\hline Female & 6,331 (70.8) & 4,501 (70.0) \\
\hline \multicolumn{3}{|l|}{ Year of diagnosis } \\
\hline 2004 & $348(3.9)$ & $290(4.5)$ \\
\hline 2005 & $392(4.4)$ & $337(5.2)$ \\
\hline 2006 & $424(4.7)$ & $375(5.8)$ \\
\hline 2007 & $595(6.6)$ & $508(7.9)$ \\
\hline 2008 & $641(7.2)$ & $532(8.3)$ \\
\hline 2009 & $796(8.9)$ & $673(10.5)$ \\
\hline 2010 & $880(9.8)$ & $743(11.6)$ \\
\hline 2011 & $996(11.1)$ & $863(13.4)$ \\
\hline 2012 & $1,143(12.8)$ & $972(15.1)$ \\
\hline 2013 & $1,352(15.1)$ & $1,136(17.7)$ \\
\hline 2014 & 1,381 (15.4) & $0(0)$ \\
\hline \multicolumn{3}{|l|}{ Age (years) } \\
\hline$>70$ & $1,592(17.8)$ & 1,023 (15.9) \\
\hline $61-70$ & $2,270(25.4)$ & $1,559(24.2)$ \\
\hline $51-60$ & $3,142(35.1)$ & $2,323(36.1)$ \\
\hline $41-50$ & 1,654 (18.5) & $1,287(20.0)$ \\
\hline$\leq 40$ & $290(3.2)$ & $237(3.7)$ \\
\hline \multicolumn{3}{|l|}{ Insurance type } \\
\hline Private insurance & $4,271(47.7)$ & $3,184(49.5)$ \\
\hline Medicare & $3,133(35.0)$ & 2,069 (32.2) \\
\hline Medicaid & $743(8.3)$ & $524(8.2)$ \\
\hline Not insured & $525(5.9)$ & $446(6.9)$ \\
\hline
\end{tabular}

Table 1 (continued)
Table 1 (continued)

\begin{tabular}{lcc}
\hline Category & $\begin{array}{c}\text { RT duration cohort } \\
\text { number (\%) }\end{array}$ & $\begin{array}{c}\text { OS cohort } \\
\text { number (\%) }\end{array}$ \\
\hline Other/unknown & $276(3.1)$ & $206(3.2)$ \\
Median household income (dollars) in zip code of patient \\
residence \\
$>63,000$ \\
$\begin{array}{l}2,634(29.4) \\
48,000-62,999\end{array}$ & $1,865(29.0)$ \\
$38,000-47,999$ & $2,379(26.6)$ & $1,734(27.0)$ \\
$<38,000$ & $1,654(18.5)$ & $1,184(18.4)$ \\
Unknown & $61(0.7)$ & $47(0.7)$
\end{tabular}

Education status (\% without high school diploma) in zip code of patient residence

$\begin{array}{lcc}<7 & 2,178(24.3) & 1,567(24.4) \\ 7.0-12.9 & 2,949(33.0) & 2,119(33.0) \\ 13-20.9 & 2,353(26.3) & 1,701(26.5) \\ \geq 21.0 & 1,409(15.7) & 997(15.5) \\ \text { Unknown } & 59(0.7) & 45(0.7)\end{array}$

Urban/rural category

Metropolitan $\geq 1$ million

$4,539(50.7) \quad 3,233(50.3)$

Metropolitan $<1$ million

$2,796(31.2) \quad 2,021(31.4)$

Urban

$1,259(14.1) \quad 923(14.4)$

Rural

$139(1.6) \quad 103(1.6)$

Unknown

$215(2.4)$

$149(2.3)$

Distance to reporting center (miles)

$\begin{array}{lcc}\leq 10 & 4,980(55.7) & 3,596(55.9) \\ 11-20 & 1,853(20.7) & 1,314(20.4) \\ 21-50 & 1,463(16.4) & 1,040(16.2) \\ >50 & 596(6.7) & 436(6.8) \\ \text { Unknown } & 56(0.6) & 43(0.7)\end{array}$

Reporting facility type

$\begin{array}{lcc}\text { Community } & 911(10.2) & 638(9.9) \\ \text { Comprehensive community } & 3,997(44.7) & 2,904(45.2) \\ \text { Academic } & 2,847(31.8) & 2,010(31.3) \\ \text { Integrated network } & 957(10.7) & 689(10.7) \\ \text { Unknown } & 236(2.6) & 188(2.9)\end{array}$

Table 1 (continued) 
Table 1 (continued)

\begin{tabular}{|c|c|c|}
\hline Category & $\begin{array}{l}\text { RT duration cohort } \\
\text { number (\%) }\end{array}$ & $\begin{array}{c}\text { OS cohort } \\
\text { number (\%) }\end{array}$ \\
\hline \multicolumn{3}{|c|}{ Reporting facility anal cancer patient volume } \\
\hline Upper third of facilities & $5,287(59.1)$ & $3,778(58.8)$ \\
\hline Middle third of facilities & 2,986 (33.4) & $2,171(33.8)$ \\
\hline Lower third of facilities & $675(7.5)$ & $480(7.5)$ \\
\hline \multicolumn{3}{|l|}{ Reporting facility location } \\
\hline Northeast & $1,843(20.6)$ & $1,296(20.2)$ \\
\hline South & $2,940(32.9)$ & $2,133(33.2)$ \\
\hline Midwest & $2,425(27.1)$ & $1,765(27.5)$ \\
\hline West & $1,504(16.8)$ & $1,047(16.3)$ \\
\hline Unknown & $236(2.6)$ & $188(2.9)$ \\
\hline \multicolumn{3}{|l|}{ Radiation plan type } \\
\hline Non-IMRT, non-proton & $4,576(51.1)$ & $3,458(53.8)$ \\
\hline IMRT, proton & $4,372(48.9)$ & 2,971 (46.2) \\
\hline \multicolumn{3}{|c|}{ Charlson/Deyo comorbidity score } \\
\hline 0 & $7,297(81.5)$ & $5,310(82.6)$ \\
\hline 1 & $1,093(12.2)$ & $756(11.8)$ \\
\hline 2 & $558(6.2)$ & $363(5.6)$ \\
\hline \multicolumn{3}{|l|}{ Clinical tumor classification } \\
\hline TO/IS & $7(0.1)$ & $4(0.1)$ \\
\hline $\mathrm{T} 1$ & $1,299(14.5)$ & $961(14.9)$ \\
\hline $\mathrm{T} 2$ & $4,579(51.2)$ & $3,329(51.8)$ \\
\hline T3 & $2,151(24.0)$ & $1,545(24.0)$ \\
\hline $\mathrm{T} 4$ & $782(8.7)$ & $557(8.7)$ \\
\hline Unknown & $130(1.5)$ & $93(1.4)$ \\
\hline \multicolumn{3}{|c|}{ Clinical nodal classification } \\
\hline No & $5,597(62.6)$ & $4,025(62.6)$ \\
\hline $\mathrm{N} 1$ & $1,150(12.9)$ & $821(12.8)$ \\
\hline N2 & $1,213(13.6)$ & $864(13.4)$ \\
\hline N3 & $865(9.7)$ & $624(9.7)$ \\
\hline Unknown & $123(1.4)$ & $95(1.5)$ \\
\hline \multicolumn{3}{|l|}{ Clinical grade } \\
\hline $\begin{array}{l}\text { Well/moderately } \\
\text { differentiated }\end{array}$ & 3,929 (43.9) & $2,817(43.8)$ \\
\hline
\end{tabular}

Table 1 (continued)
Table 1 (continued)

\begin{tabular}{lcc}
\hline Category & $\begin{array}{c}\text { RT duration cohort } \\
\text { number (\%) }\end{array}$ & $\begin{array}{c}\text { OS cohort } \\
\text { number (\%) }\end{array}$ \\
\hline $\begin{array}{l}\text { Poorly differentiated/ } \\
\text { undifferentiated, anaplastic }\end{array}$ & $2,538(28.4)$ & $1,847(28.7)$ \\
Unknown & $2,481(27.7)$ & $1,765(27.5)$ \\
Chemotherapy administered & & \\
Multi-agent & $7,780(86.9)$ & $5,560(86.5)$ \\
Single agent & $805(9.0)$ & $575(8.9)$ \\
Unknown & $363(4.1)$ & $294(4.6)$ \\
\hline
\end{tabular}

AAPI, Asian-American and Pacific Islander; IMRT, intensitymodulated radiation therapy; IS, in situ.

underestimates the number of missed days for some patients but was felt to be the most conservative technique given that the exact planned number of treatment days is not recorded in the NCDB.

Negative binomial regression was used to assess the effect of demographic and prognostic factors on duration of RT. An offset was used to adjust for the number of fractions delivered. Cox proportional hazards regression model was used for OS analysis. Schoenfeld residual analysis was used to assess the proportional hazards assumption. The penalized spline regression method was used to obtain adjusted hazard ratio (HR) of OS according to fractions delivered per week and missed days of RT as continuous variables. A cutoff value dichotomizing fractions delivered per week was determined using the minimum $P$ value approach (30). All tests were two-sided and $\mathrm{P}<0.05$ was used as criteria for statistical significance. All statistical analyses were performed with statistical software packages SAS/ STAT version 9.4 (SAS Institute Inc.) or R (version 3.3.1).

\section{Results}

\section{Patient cobort characteristics}

A final cohort of 8,948 patients with non-metastatic SCCA treated with definitive CRT was used for the MVA to determine factors associated with total duration of RT. Table 1 summarizes the cohort's demographics, prognostic characteristics, and treatment factors. Cohort characteristics include a majority of non-Hispanic white patients $(81.1 \%)$, mostly female patients $(70.8 \%)$, a near even distribution 
of non-IMRT (51.1\%) or IMRT (48.9\%), and a majority receiving multi-agent chemotherapy $(86.9 \%)$. The mean of total elapsed days of RT was 48.5 days [SD (standard deviation) $=9.5$ ], and the median was 46.0 days. The mean total dose was 53.46 Gy $(\mathrm{SD}=3.98)$, and the median was 54.00 Gy. The mean fractions delivered were 29.5 fractions $(\mathrm{SD}=2.3)$ with a median of 30.0 fractions. The mean fractions delivered per week was $4.37 \mathrm{fx} /$ week $(\mathrm{SD}=0.65)$ with a median of $4.53 \mathrm{fx} /$ week. The mean missed days of RT were 6.5 days $(\mathrm{SD}=8.2)$ with a median of 3 days.

\section{MVA of factors impacting duration of $R T$}

An MVA was completed to assess the relative risk (RR) that factors included in Table 1 may contribute to total duration of RT. The results of this analysis are shown in Table 2. Female gender was associated with a longer duration of RT [RR, 1.03; 95\% confidence interval (CI), 1.02-1.04]. Patients diagnosed in the years 2008-2014 had a significant decrease in total RT duration relative to the reference variable of $2004(\mathrm{P}<0.05)$. Patients without private insurance were more likely to have a longer duration of RT, particularly among patients with Medicaid (RR, 1.07; 95\% CI, 1.05-1.08). Living >50 miles from a reporting center was associated with a shorter duration of RT relative to patients living within 10 miles of a reporting center (RR, 0.97; 95\% CI, 0.96-0.99). Treatment at an academic center was associated with a shorter duration of RT relative to a community hospital (RR, 0.98; 95\% CI, 0.97-1.00). Treatment at high volume facilities was associated with a significantly shorter duration of RT relative to treatment at intermediate and low volume facilities. Patients treated with IMRT relative to Non-IMRT were associated with a shorter duration of RT (RR, 0.97; 95\% CI, 0.96-0.97). Charlson/ Deyo score $\geq 2$ was associated with a longer duration of RT (RR, 1.03; 95\% CI, 1.02-1.05). More advanced AJCC T and $\mathrm{N}$ stages were associated with significantly longer durations of RT. Patients treated with single-agent chemotherapy had a shorter duration of RT relative to those receiving multiagent chemotherapy (RR, 0.99; 95\% CI, 0.97-1.00).

\section{Impact of radiotherapy prolongation on OS (Figures 2,3)}

After excluding patients with no data on time from diagnosis to death or last contact and excluding patients with prior malignancies, 6,429 patients were included in the OS analysis (Table 3). The number of fractions delivered
Table 2 Multivariable analyses on the effects of patient demographic, treatment/treatment center, and prognostic characteristics on total radiotherapy duration

\begin{tabular}{|c|c|c|}
\hline Category & $\mathrm{RR}(95 \% \mathrm{Cl})$ & $P$ value \\
\hline \multicolumn{3}{|l|}{ Race/ethnicity } \\
\hline Non-Hispanic White & Reference & \\
\hline Hispanic & $1.00(0.98,1.02)$ & 0.819 \\
\hline Non-Hispanic Black & $1.00(0.98,1.01)$ & 0.498 \\
\hline AAPI & $0.98(0.94,1.02)$ & 0.252 \\
\hline Other/unknown & $1.01(0.99,1.02)$ & 0.486 \\
\hline \multicolumn{3}{|l|}{ Gender } \\
\hline Male & Reference & \\
\hline Female & $1.03(1.02,1.04)$ & $<0.001$ \\
\hline \multicolumn{3}{|l|}{ Year of diagnosis } \\
\hline 2004 & Reference & \\
\hline 2005 & $0.99(0.97,1.02)$ & 0.621 \\
\hline 2006 & $1.01(0.98,1.03)$ & 0.482 \\
\hline 2007 & $0.99(0.97,1.01)$ & 0.481 \\
\hline 2008 & $0.98(0.96,1.00)$ & 0.044 \\
\hline 2009 & $0.98(0.96,1.00)$ & 0.033 \\
\hline 2010 & $0.97(0.95,0.99)$ & 0.011 \\
\hline 2011 & $0.96(0.94,0.98)$ & $<0.001$ \\
\hline 2012 & $0.95(0.93,0.97)$ & $<0.001$ \\
\hline 2013 & $0.95(0.93,0.97)$ & $<0.001$ \\
\hline 2014 & $0.95(0.93,0.97)$ & $<0.001$ \\
\hline \multicolumn{3}{|l|}{ Age (years) } \\
\hline$>70$ & Reference & \\
\hline $61-70$ & $0.99(0.98,1.00)$ & 0.158 \\
\hline $51-60$ & $0.99(0.98,1.00)$ & 0.174 \\
\hline $41-50$ & $1.00(0.99,1.02)$ & 0.702 \\
\hline$\leq 40$ & $0.99(0.94,1.04)$ & 0.675 \\
\hline \multicolumn{3}{|l|}{ Insurance type } \\
\hline Private insurance & Reference & \\
\hline Medicare & $1.03(1.02,1.04)$ & $<0.001$ \\
\hline Medicaid & $1.07(1.05,1.08)$ & $<0.001$ \\
\hline Not insured & $1.02(1.01,1.04)$ & 0.010 \\
\hline Other/unknown & $1.04(1.02,1.06)$ & $<0.001$ \\
\hline
\end{tabular}

Table 2 (continued) 
Table 2 (continued)

\begin{tabular}{lcc}
\hline Category & $\mathrm{RR}(95 \% \mathrm{Cl})$ & $\mathrm{P}$ value \\
\hline $\begin{array}{l}\text { Median household income (dollars) in zip code of patient } \\
\text { residence } \\
>63,000\end{array}$ & Reference & \\
$48,000-62,999$ & $1.01(1.00,1.02)$ & 0.250 \\
$38,000-47,999$ & $1.00(0.99,1.02)$ & 0.697 \\
$<38,000$ & $1.01(0.99,1.02)$ & 0.308 \\
Unknown & $0.92(0.72,1.18)$ & 0.518
\end{tabular}

Education status (\% without high school diploma) in zip code of patient residence

$<7$
$7.0-12.9$
$13-20.9$
$\geq 21.0$
Unknown
Urban/rural category
Metropolitan $\geq 1$ million
Metropolitan $<1$ million
Urban
Rural
Unknown

Reference

0.506

$1.02(1.00,1.03)$

0.011

$1.01(0.99,1.02)$

0.533

$1.12(0.86,1.46)$

0.408

Distance to reporting center (miles)

$\leq 10$
$11-20$
$21-50$
$>50$
Unknown

Reporting facility type

\begin{tabular}{lcc} 
Community & Reference & \\
Comprehensive community & $0.99(0.97,1.00)$ & 0.049 \\
Academic & $0.98(0.97,1.00)$ & 0.019 \\
Integrated network & $1.01(0.99,1.02)$ & 0.479 \\
Reporting facility anal cancer patient volume & \\
Upper third of facilities & Reference & \\
Middle third of facilities & $1.01(1.01,1.02)$ & $<0.001$ \\
Lower third of facilities & $1.02(1.00,1.03)$ & 0.015 \\
\hline
\end{tabular}

Table 2 (continued)

$1.01(0.99,1.02) \quad 0.353$

$1.02(0.99,1.05) \quad 0.222$

$0.98(0.96,1.01) \quad 0.223$
Table 2 (continued)

\begin{tabular}{lcc}
\hline Category & $\mathrm{RR}(95 \% \mathrm{Cl})$ & $\mathrm{P}$ value \\
\hline Reporting facility location & Reference & \\
Northeast & $1.00(0.99,1.01)$ & 0.656 \\
South & $0.99(0.98,1.00)$ & 0.091 \\
Midwest & $0.97(0.95,0.98)$ & $<0.001$ \\
West & & \\
Radiation plan type & Reference & \\
Non-IMRT, non-proton & $0.97(0.96,0.97)$ & $<0.001$ \\
IMRT, proton &
\end{tabular}

Charlson/Deyo comorbidity score

0

Reference

1

2

$1.01(0.99,1.02)$

0.342

$1.03(1.02,1.05)$

$<0.001$

Clinical tumor classification

TO/IS

$0.93(0.82,1.06)$

0.289

T1

T2

T3

T4

Reference

$1.02(1.01,1.03) \quad<0.001$

$1.02(1.01,1.04)<0.001$

Clinical nodal classification

NO

Reference

N1

N2

N3

Unknown

$1.03(1.02,1.05)$

$<0.001$

Clinical grade

Well/moderately differentiated

Poorly differentiated/

undifferentiated, anaplastic

Unknown

$1.00(0.99,1.01)$

0.623

$1.02(1.00,1.03)$

0.006

$1.01(1.00,1.03)$

0.045

$0.99(0.96,1.02)$

0.552

Chemotherapy administered

Multi-agent

Reference

$1.00(0.99,1.01)$

0.764

$1.00(1.00,1.01)$

0.356

Single agent

Unknown

Reference

$0.99(0.97,1.00) \quad 0.031$

$1.02(1.00,1.04) \quad 0.016$

Dose per fraction

$1.05(1.01,1.09) \quad 0.009$

AAPI, Asian-American and Pacific Islander; IMRT, intensitymodulated radiation therapy; IS, in situ. 

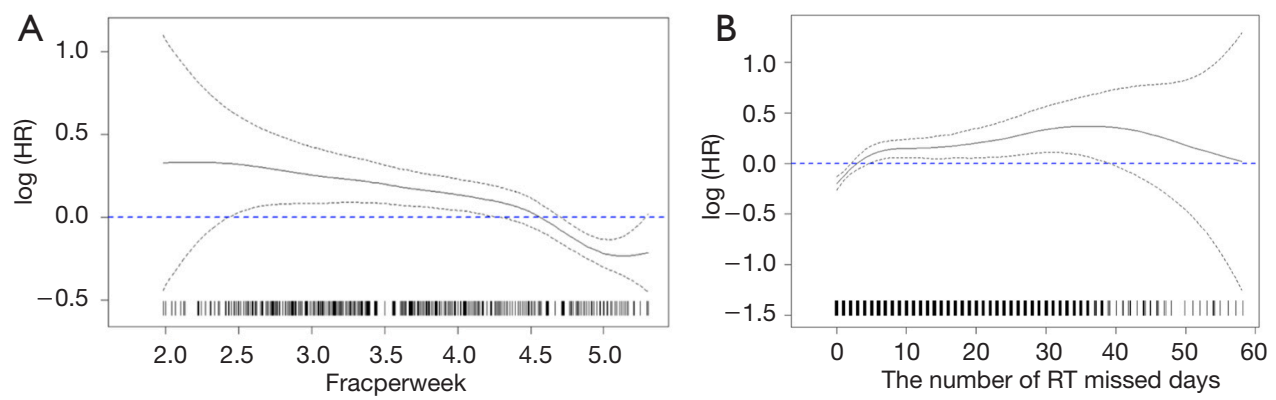

Figure 2 Multivariable analyses of risk of death in relation to radiation therapy treatment schedules. (A) Adjusted hazard ratio of death relative to fractions delivered per week as a continuous variable. Dashed lines represent the upper and lower bound of the confidence interval for the hazard ratio. The vertical lines at the base of the graph show the frequency of patients treated at each fraction per week interval. Note: hazard ratios are shown on a log scale. (B) Adjusted hazard ratio of death relative to the number of RT missed days as a continuous variable. Higher values represent an increased risk of death. Dashed lines represent the upper and lower bound of the confidence interval for the hazard ratio. The vertical lines at the base of the graph show the frequency of patients treated at each value of missed RT days. Note: hazard ratios are shown on a log scale.
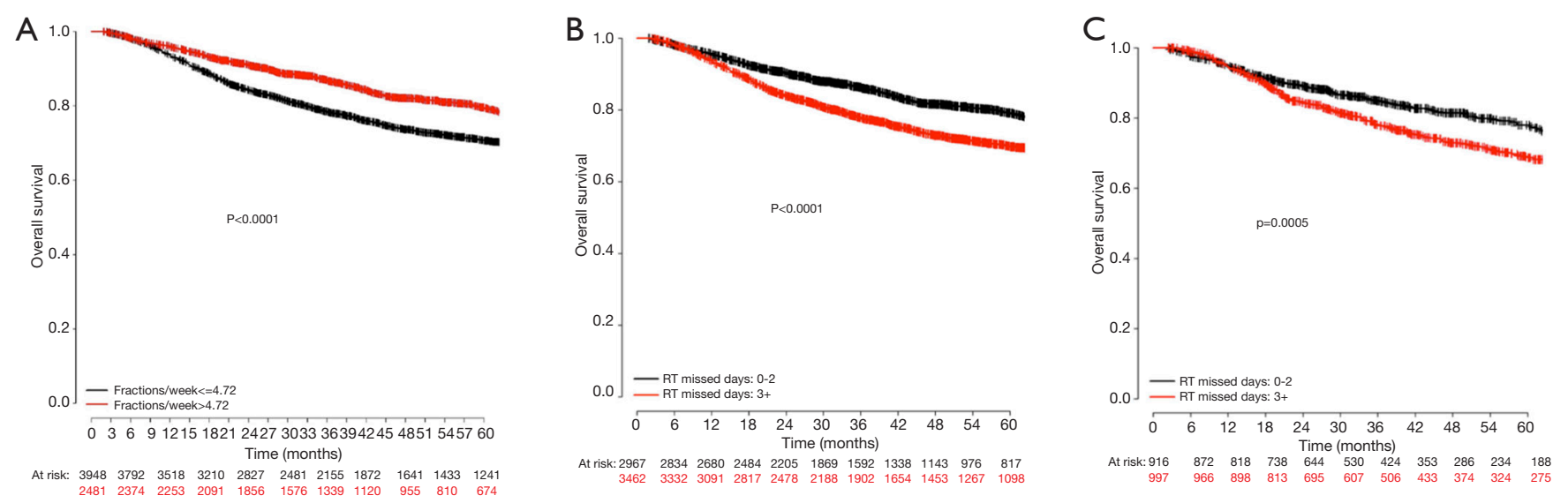

Figure 3 Kaplan-Meier plots of overall survival in relation to radiation therapy treatment schedules. (A) Kaplan-Meier plots comparing overall survival based on fractions delivered per week. Key: Red $\longrightarrow 4.72$ fractions delivered per week. Black $-\leq 4.72$ fractions delivered per week. (B) Kaplan-Meier plots comparing overall survival based on RT missed days. Key: Red—RT missed days: 3+. Black—RT missed days: 0-2. (C) Kaplan-Meier plots comparing overall survival based on RT missed days among patients treated with 54 Gy in 30 fractions. Key: red-RT missed days: 3+. Black—RT missed days: 0-2.

per week was independently associated with OS (HR, 0.79; 95\% CI, 0.73-0.85). The minimum $\mathrm{P}$ value approach was used to dichotomize this variable (30). The value was determined to be 4.72 fractions per week, and the MVA was then repeated with fractions per week as a categorical variable $(\leq 4.72$ vs. $>4.72)$. Patients treated at a rate $>4.72$ fractions per week had greater OS relative to the group treated at a rate $\leq 4.72$ fractions per week (HR, 0.70; 95\% CI, 0.63-0.79). Figure $2 A$ displays the HR for OS relative to fractions delivered per week and shows that the HR for
OS increased as the rate of treatment decreased. Figure $3 \mathrm{~A}$ displays the difference in OS between the cohort treated with $>4.72$ fractions per week and the cohort treated with $\leq 4.72$ fractions per week. Additional factors associated with improved OS on MVA included female gender, younger age, private insurance, treatment in an academic center, treatment in a high volume facility, treatment with IMRT compared to Non-IMRT, Charlson/Deyo score of 0 , and less advanced AJCC $\mathrm{T}$ and $\mathrm{N}$ stages.

To better translate these results for clinical practice, 
Table 3 Multivariable analyses on the impact of fractions delivered per week, patient demographic, treatment/treatment center, and prognostic characteristics on overall survival

\begin{tabular}{lcc}
\hline Category & HR $(95 \% \mathrm{Cl})$ & P value \\
\hline Race/ethnicity & Reference & \\
Non-Hispanic White & $0.79(0.60,1.06)$ & 0.114 \\
Hispanic & $1.08(0.89,1.30)$ & 0.454 \\
Non-Hispanic Black & $0.56(0.29,1.08)$ & 0.084 \\
AAPI & $0.94(0.75,1.18)$ & 0.579 \\
Other/unknown & & \\
Gender & Reference & \\
Male & $0.52(0.46,0.58)$ & $<0.001$ \\
Female & & \\
Age (years) & Reference & \\
$>70$ & $0.65(0.56,0.76)$ & $<0.001$ \\
$61-70$ & $0.55(0.46,0.65)$ & $<0.001$ \\
$51-60$ & $0.49(0.40,0.60)$ & $<0.001$ \\
$41-50$ & $0.31(0.14,0.71)$ & 0.005 \\
$\leq 40$ & &
\end{tabular}

Insurance type

Private insurance

Reference

$\begin{array}{lll}\text { Medicare } & 1.39(1.20,1.61) & <0.001 \\ \text { Medicaid } & 1.69(1.40,2.05) & <0.001 \\ \text { Not insured } & 1.44(1.16,1.78) & <0.001 \\ \text { Other/unknown } & 1.12(0.83,1.51) & 0.452\end{array}$

Median household income (dollars) in zip code of patient residence

$$
\begin{aligned}
& >63,000 \\
& 48,000-62,999 \\
& 38,000-47,999 \\
& <38,000
\end{aligned}
$$

Unknown

Education status (\% without high school diploma) in zip code of patient residence

\begin{tabular}{lcc}
$<7$ & Reference & \\
$7.0-12.9$ & $1.07(0.91,1.26)$ & 0.393 \\
$13-20.9$ & $1.10(0.91,1.32)$ & 0.332 \\
$\geq 21.0$ & $0.92(0.73,1.16)$ & 0.467 \\
Unknown & $0.25(0.03,2.45)$ & 0.233 \\
\hline
\end{tabular}

Table 3 (continued)
Table 3 (continued)

\begin{tabular}{lcc}
\hline Category & $\mathrm{HR}(95 \% \mathrm{Cl})$ & $\mathrm{P}$ value \\
\hline Urban/rural category & & \\
Metropolitan $\geq 1$ million & Reference & \\
Metropolitan $<1$ million & $0.88(0.77,1.00)$ & 0.051 \\
Urban & $0.87(0.72,1.06)$ & 0.16 \\
Rural & $0.93(0.62,1.39)$ & 0.716 \\
Unknown & $0.95(0.65,1.39)$ & 0.796
\end{tabular}

Distance to reporting center (miles)

$\begin{array}{lcc}\leq 10 & \text { Reference } & \\ 11-20 & 0.96(0.83,1.10) & 0.538 \\ 21-50 & 1.05(0.89,1.24) & 0.56 \\ >50 & 1.10(0.87,1.40) & 0.427 \\ \text { Unknown } & 1.48(0.44,4.93) & 0.524 \\ \text { Reporting facility type } & & \\ \text { Community } & \text { Reference } & \\ \text { Comprehensive community } & 0.85(0.71,1.02) & 0.081 \\ \text { Academic } & 0.76(0.62,0.93) & 0.009 \\ \text { Integrated network } & 0.93(0.73,1.19) & 0.56\end{array}$

Reporting facility anal cancer patient volume

$\begin{array}{lcc}\text { Upper third of facilities } & \text { Reference } & \\ \text { Middle third of facilities } & 1.14(1.01,1.28) & 0.038 \\ \text { Lower third of facilities } & 1.03(0.83,1.28) & 0.773\end{array}$

Reporting facility location

$\begin{array}{lcc}\text { Northeast } & \text { Reference } & \\ \text { South } & 1.15(0.98,1.34) & 0.078 \\ \text { Midwest } & 1.15(0.98,1.35) & 0.089 \\ \text { West } & 1.00(0.83,1.20) & 0.97 \\ \text { Radiation plan type } & \text { Reference } & \\ \text { Non-IMRT, non-proton } & 0.86(0.77,0.96) & 0.007 \\ \text { IMRT, proton } & & \\ \text { Charlson/Deyo comorbidity score } & \\ 0 & \text { Reference } & \\ 1 & 1.44(1.24,1.66) & <0.001 \\ 2 & 1.91(1.58,2.31) & <0.001 \\ \text { Clinical tumor classification } & & \mathrm{NA} \\ \text { TO/IS } & \mathrm{NA} & \end{array}$

Table 3 (continued) 
Table 3 (continued)

\begin{tabular}{|c|c|c|}
\hline Category & $\mathrm{HR}(95 \% \mathrm{Cl})$ & $P$ value \\
\hline $\mathrm{T} 1$ & Reference & \\
\hline $\mathrm{T} 2$ & $1.32(1.10,1.59)$ & 0.004 \\
\hline T3 & $1.95(1.60,2.38)$ & $<0.001$ \\
\hline $\mathrm{T} 4$ & $2.53(2.02,3.18)$ & $<0.001$ \\
\hline Unknown & $1.66(1.09,2.54)$ & 0.018 \\
\hline \multicolumn{3}{|l|}{ Clinical nodal classification } \\
\hline No & Reference & \\
\hline N1 & $1.30(1.10,1.53)$ & 0.002 \\
\hline N2 & $1.45(1.25,1.69)$ & $<0.001$ \\
\hline N3 & $1.55(1.31,1.83)$ & $<0.001$ \\
\hline Unknown & $1.25(0.84,1.85)$ & 0.27 \\
\hline \multicolumn{3}{|l|}{ Clinical grade } \\
\hline $\begin{array}{l}\text { Well/moderately } \\
\text { differentiated }\end{array}$ & Reference & \\
\hline $\begin{array}{l}\text { Poorly differentiated/ } \\
\text { undifferentiated, anaplastic }\end{array}$ & $1.05(0.93,1.19)$ & 0.445 \\
\hline Unknown & $0.97(0.85,1.10)$ & 0.613 \\
\hline Dose per fraction & $1.00(1.00,1.01)$ & 0.338 \\
\hline $\begin{array}{l}\text { Fractions delivered per week } \\
\text { (continuous) }^{*}\end{array}$ & $0.79(0.73,0.85)$ & $<0.001$ \\
\hline \multicolumn{3}{|c|}{ Fractions delivered per week (categorical)* } \\
\hline$\leq 4.72$ & Reference & \\
\hline$>4.72$ & $0.70(0.63,0.79)$ & $<0.001$ \\
\hline
\end{tabular}

*, each variable was run separately with OS analysis. AAPI, Asian-American and Pacific Islander; IMRT, intensity-modulated radiation therapy; IS, in situ.

estimated number of RT days missed was calculated as described above. RT missed days was significantly associated with a decrease in OS when considered as a continuous variable (HR, 1.04; 95\% CI, 1.03-1.06) as seen in Figure $2 B$ or as a categorical variable dichotomized as $0-2$ vs. 3+ missed days (HR, 1.42; 95\% CI, 1.27-1.59) as seen in Figure 3B. Estimated 5-year OS was 79.2\% (95\% CI, 77.4-81.0) for $0-2$ days versus $69.9 \%$ (95\% CI, 68.1-71.6) for $3+$ missed days. To further evaluate whether longer delays reduced 5 -year OS relative to shorter delays patients with 0-2 days of delay, 3-14 days of delay, and 14+ days of delay were compared. Patients in the 14+ days of delay group (HR, 1.73; 95\% CI, 1.50-1.98) had a significantly reduced 5-year OS when compared to the 0-2 days of delay group (Reference). Those with 3-14 days delay also had significantly worse survival relative to those with $0-2$ days (HR, 1.45; 95\% CI, 1.29-1.63), although the difference was numerically less compared to those with 14+ days delay as seen in Figure 4. A subset OS analysis was performed only utilizing patients who received the most common fractionation schedule of 54 Gy in 30 fractions $(n=1,913)$. This analysis found a significant decrease in OS for patients with 3 or more missed days (HR, 1.40; 95\% CI, 1.14-1.72) (Figure 3C).

\section{Discussion}

This analysis of patients with SCCA treated with definitive CRT found that prolongation of RT was independently associated with reduced OS. In addition, reduction in OS had the greatest effect when RT was delivered at a rate of 4.72 fractions or less per week, about 2 days of delayed treatment. These data indicate that any delay in RT should be avoided in patients with SCCA receiving definitive CRT when practical, and attempts should be made to compensate for treatment delays.

Previous studies of SCCA with planned gaps during RT have supported improved outcomes with shorter RT duration. Two smaller reports found that delays in RT were associated with reduced local or locoregional control (LRC) $(12,13)$. A larger study of 305 anal cancer patients treated with a 4-6-week gap during RT prior to boost delivery found that a gap $>38$ days was associated with reduced DFS on MVA (14).

Additional studies that did not include treatment gaps also support minimizing RT prolongation. A small study evaluating CRT found that a CRT duration $<40$ days resulted in a trend towards improved LRC, OS, and DFS (31). A recent analysis from the NCDB evaluating the effect of facility volume found on multivariate analysis that patients with an RT duration $>45$ days had worse OS; however, this study was not designed to specifically evaluate effects of RT duration (32).

In contrast, other studies have found no association between RT duration and outcomes in anal cancer. Two small studies of anal cancer patients receiving definitive CRT found no statistically significant difference in any oncologic outcomes based on treatment prolongation $(15,33)$. A larger study examining 194 patients treated with definitive CRT found no difference in 5-year DFS between patients with greater than or less than 2 weeks of 


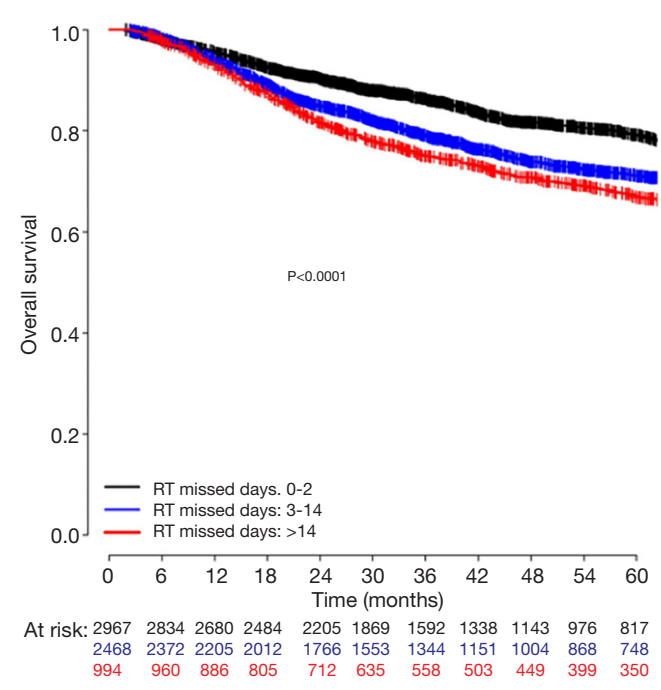

Figure 4 Kaplan-Meier plots comparing overall survival based on RT missed days. Key: black—RT missed days 0-2; blue-RT missed days 3-14; red-RT missed days $>14$.

treatment delays (16). Finally, a pooled risk analysis of two RTOG trials with 937 patients, approximately one third of whom were treated with induction chemotherapy prior to concurrent CRT, showed that overall treatment time (including induction chemotherapy time) was associated with increased risk of local failure. However, duration of RT specifically did not have a significant impact on local failure or other endpoints (17).

The current NCDB analysis concurred with previous studies that showed improved outcomes when delays were minimized. As noted above, prior studies evaluating duration of RT included smaller sample sizes, precluding definitive conclusions regarding the impact of RT duration on OS (11-16,31,33). Although the pooled analysis, consisting of 937 patients, utilized a larger sample size, approximately one-third of the patients received induction chemotherapy prior to concurrent CRT (17). This regimen may have confounded results, and induction chemotherapy is not currently standard of care for SCCA (8). Additionally, many of the studies utilized long treatment breaks to evaluate the effects of RT duration. These scheduled gaps do not accurately reflect the intermittent manner in which treatment delays occur. This current NCDB analysis of 6,429 patients improves on prior studies by providing increased power to detect a difference in OS while limiting the patient population to patients receiving standard of care concurrent CRT.

These conclusions should further discourage unnecessary breaks in SCCA treatment. Both the NCCN and The Royal College of Radiologists (RCR) recommend minimizing delays during RT $(8,34)$. The RCR has labeled SCCA as a Category 1 malignancy, defined as a rapidly growing tumor type for which interruptions greater than 2 days above the initial prescription duration should be avoided. When feasible and safe for the patient, the Royal College of Radiologists has published guidelines that recommend consideration of an accelerated treatment time to maintain the treatment schedule and/or other compensatory treatment measures (34). The current study indicates that even treatment delays of this length should be avoided when practical and that any delays may result in a reduction in OS.

The primary cause of delay during CRT treatment of SCCA has been identified as severity of side effects to CRT $(6,9,10)$. Attempted modifications to current standard regimens have been generally unsuccessful at reducing toxicity and/or maintaining outcomes $(7,35)$. IMRT, though, has shown potential to improve outcomes and reduce delays. A recent trial showed IMRT reduced toxicity, shortened treatment interruptions, and had comparable outcomes to conventional RT (9). An NCDB study evaluating use of IMRT found a significant reduction in treatment time and improved OS (36). An additional Veteran Affairs database study found IMRT was associated with reduced treatment breaks (37). Based on these results the NCCN recommends IMRT over 3D-conformal RT (8). The current analysis also showed that IMRT was significantly associated with a shorter duration of RT. Therefore, when possible IMRT should be considered.

In this study female patients, patients without private insurance, patients with more comorbidities, and patients with more advanced disease had longer durations of RT. Additional attention should be considered in these patients to minimize RT delays. Based on these results, it appears simply having insurance such as Medicaid of Medicare is not protective against treatment delays relative to having private insurance. Further investigation into this disparity may prove important. Numerous studies have evaluated the factors that predict delays in treatment initiation; however, few have evaluated factors that affect delays during treatment $(38,39)$. Future studies should attempt to elucidate these disparities.

There are inherent limitations to performing a retrospective database analysis. Variation of outcomes could be due to factors not reported in the dataset and therefore not accounted for by analysis. Important endpoints such as 
LC, colostomy-free survival, and DFS are not provided in the dataset. Additionally, the impact of HIV status could not be assessed as it was not included in the NCDB, and the impact of HPV status could not be assessed as only 869 patients in this dataset had a reported HPV status. However, strengths of this study include the large dataset composed of a population that is geographically and racially diverse and the extensive sociodemographic information available.

\section{Conclusions}

In conclusion, this study demonstrates that length of RT for localized SCCA is independently associated with OS. The most significant impact was noted when the treatment rate fell below 4.72 fractions per week, about 2 days of RT delay. Efforts should be made to minimize treatment delays in general and when possible compensate for treatment interruptions to maintain an overall treatment rate that exceeds 4.72 fractions per week by the end of treatment. Future studies should attempt to evaluate the impact of RT duration on OS in other datasets and delineate the relationship between RT duration and LC, DFS, toxicity, and colostomy-free survival.

\section{Acknowledgments}

This research was presented as an abstract at the American Society for Radiation Oncology (ASTRO) 2018 Conference. Funding: This work was supported by the University of Miami Miller School of Medicine/Sylvester Comprehensive Cancer Center Department of Radiation Oncology.

\section{Footnote}

Conflicts of Interest: Dr. Ramey received travel accommodations from Intellisphere, but is not related to current research. Dr. Ahmed is part owner of W\&L Dosimetry Services. Dr. Mellon received travel accommodations from ViewRay, unrelated to this research. This research was presented as an abstract at the American Society for Radiation Oncology (ASTRO) 2018 conference.

Ethical Statement: The authors are accountable for all aspects of the work in ensuring that questions related to the accuracy or integrity of any part of the work are appropriately investigated and resolved. Since de-identified data was used in this analysis, it was declared exempt from Institutional Review Board oversight by the sponsoring institution.
Open Access Statement: This is an Open Access article distributed in accordance with the Creative Commons Attribution-NonCommercial-NoDerivs 4.0 International License (CC BY-NC-ND 4.0), which permits the noncommercial replication and distribution of the article with the strict proviso that no changes or edits are made and the original work is properly cited (including links to both the formal publication through the relevant DOI and the license). See: https://creativecommons.org/licenses/by-nc-nd/4.0/.

\section{References}

1. Siegel RL, Miller KD, Jemal A. Cancer statistics, 2019. CA Cancer J Clin 2019;69:7-34.

2. Nelson RA, Levine AM, Bernstein L, et al. Changing patterns of anal canal carcinoma in the United States. J Clin Oncol 2013;31:1569-75.

3. Frisch $M$, Fenger C, van den Brule AJ, et al. Variants of squamous cell carcinoma of the anal canal and perianal skin and their relation to human papillomaviruses. Cancer Res 1999;59:753-7.

4. Melbye M, Frisch M. The role of human papillomaviruses in anogenital cancers. Semin Cancer Biol 1998;8:307-13.

5. Shiels MS, Kreimer AR, Coghill AE, et al. Anal Cancer Incidence in the United States, 1977-2011: Distinct Patterns by Histology and Behavior. Cancer Epidemiol Biomarkers Prev 2015;24:1548-56.

6. Ajani JA, Winter KA, Gunderson LL, et al. Fluorouracil, mitomycin, and radiotherapy vs fluorouracil, cisplatin, and radiotherapy for carcinoma of the anal canal: a randomized controlled trial. JAMA 2008;299:1914-21.

7. James RD, Glynne-Jones R, Meadows HM, et al. Mitomycin or cisplatin chemoradiation with or without maintenance chemotherapy for treatment of squamouscell carcinoma of the anus (ACT II): a randomised, phase 3, open-label, 2 × 2 factorial trial. Lancet Oncol 2013;14:516-24.

8. Network NCC. NCCN Clinical Practice Guidelines in Oncology Anal Carcinoma Version 1.2018. 2018. Available online: https://www.nccn.org/professionals/physician_gls/ pdf/anal.pdf, accessed April 28, 2018.

9. Kachnic LA, Winter K, Myerson RJ, et al. RTOG 0529: a phase 2 evaluation of dose-painted intensity modulated radiation therapy in combination with 5 -fluorouracil and mitomycin-C for the reduction of acute morbidity in carcinoma of the anal canal. Int J Radiat Oncol Biol Phys 2013;86:27-33.

10. Roohipour R, Patil S, Goodman KA, et al. Squamous- 
cell carcinoma of the anal canal: predictors of treatment outcome. Dis Colon Rectum 2008;51:147-53.

11. Allal AS, Mermillod B, Roth AD, et al. The impact of treatment factors on local control in T2-T3 anal carcinomas treated by radiotherapy with or without chemotherapy. Cancer 1997;79:2329-35.

12. Graf R, Wust P, Hildebrandt B, et al. Impact of overall treatment time on local control of anal cancer treated with radiochemotherapy. Oncology 2003;65:14-22.

13. Weber DC, Kurtz JM, Allal AS. The impact of gap duration on local control in anal canal carcinoma treated by split-course radiotherapy and concomitant chemotherapy. Int J Radiat Oncol Biol Phys 2001;50:675-80.

14. Deniaud-Alexandre E, Touboul E, Tiret E, et al. Results of definitive irradiation in a series of 305 epidermoid carcinomas of the anal canal. Int J Radiat Oncol Biol Phys 2003;56:1259-73.

15. Meyer A, Meier Zu Eissen J, Karstens JH, et al. Chemoradiotherapy in patients with anal cancer: impact of length of unplanned treatment interruption on outcome. Acta Oncol 2006;45:728-35.

16. Myerson RJ, Outlaw ED, Chang A, et al. Radiotherapy for epidermoid carcinoma of the anus: thirty years' experience. Int J Radiat Oncol Biol Phys 2009;75:428-35.

17. Ben-Josef E, Moughan J, Ajani JA, et al. Impact of overall treatment time on survival and local control in patients with anal cancer: a pooled data analysis of Radiation Therapy Oncology Group trials 87-04 and 98-11. J Clin Oncol 2010;28:5061-6.

18. Bese NS, Hendry J, Jeremic B. Effects of prolongation of overall treatment time due to unplanned interruptions during radiotherapy of different tumor sites and practical methods for compensation. Int J Radiat Oncol Biol Phys 2007;68:654-61.

19. González Ferreira JA, Jaen Olasolo J, Azinovic I, et al. Effect of radiotherapy delay in overall treatment time on local control and survival in head and neck cancer: Review of the literature. Rep Pract Oncol Radiother 2015;20:328-39.

20. Shaikh T, Handorf EA, Murphy CT, et al. The Impact of Radiation Treatment Time on Survival in Patients With Head and Neck Cancer. Int J Radiat Oncol Biol Phys 2016;96:967-75.

21. Roman J, Dissaux G, Gouillou M, et al. Prolonged Overall Treatment Time and Lack of Skin Rash Negatively Impact Overall Survival in Locally Advanced Head and Neck Cancer Patients Treated with Radiotherapy and
Concomitant Cetuximab. Target Oncol 2017;12:505-12.

22. Fyles A, Keane TJ, Barton M, et al. The effect of treatment duration in the local control of cervix cancer. Radiother Oncol 1992;25:273-9.

23. Girinsky T, Rey A, Roche B, et al. Overall treatment time in advanced cervical carcinomas: a critical parameter in treatment outcome. Int J Radiat Oncol Biol Phys 1993;27:1051-6.

24. Cancer ACoSCo. American College of Surgeons: National Cancer Database: Tools, Reports, and Resources. 2016.

25. Bilimoria KY, Stewart AK, Winchester DP, et al. The National Cancer Data Base: a powerful initiative to improve cancer care in the United States. Ann Surg Oncol 2008;15:683-90.

26. Boffa DJ, Rosen JE, Mallin K, et al. Using the National Cancer Database for Outcomes Research: A Review. JAMA Oncol 2017;3:1722-8.

27. Organization WH. International classification of diseases for oncology: ICD-O. 3 ed. 2013.

28. Peiffert D, Tournier-Rangeard L, Gerard JP, et al. Induction chemotherapy and dose intensification of the radiation boost in locally advanced anal canal carcinoma: final analysis of the randomized UNICANCER ACCORD 03 trial. J Clin Oncol 2012;30:1941-8.

29. Surgeons ACo. Getting Started-A User's Guide. Available online: http://ncdbpuf.facs.org/node/274.

30. Mazumdar M, Glassman JR. Categorizing a prognostic variable: review of methods, code for easy implementation and applications to decision-making about cancer treatments. Stat Med 2000;19:113-32.

31. Constantinou EC, Daly W, Fung CY, et al. Time-dose considerations in the treatment of anal cancer. Int J Radiat Oncol Biol Phys 1997;39:651-7.

32. Amini A, Jones BL, Ghosh D, et al. Impact of facility volume on outcomes in patients with squamous cell carcinoma of the anal canal: Analysis of the National Cancer Data Base. Cancer 2017;123:228-36.

33. Konski A, Garcia M Jr, John M, et al. Evaluation of planned treatment breaks during radiation therapy for anal cancer: update of RTOG 92-08. Int J Radiat Oncol Biol Phys 2008;72:114-8.

34. The Royal College of Radiologists. The Timely Delivery of Radical Radiotherapy: Standards and Guidelines for the Management of Unscheduled Treatment Interruptions, Fourth Edition. The Royal College of Radiologists; 2019.

35. Gunderson LL, Winter KA, Ajani JA, et al. Long-term update of US GI intergroup RTOG 98-11 phase III trial for anal carcinoma: survival, relapse, and colostomy failure 
with concurrent chemoradiation involving fluorouracil/ mitomycin versus fluorouracil/cisplatin. J Clin Oncol 2012;30:4344-51.

36. Elson JK, Kharofa JR. IMRT Improves Survival and Reduces Treatment Time in Squamous Cell Carcinoma of the AnalCanal: A National Cancer Database Study [Abstract]. Int J Radiat Oncol Biol Phys 2017;99:E146.

37. Bryant AK, Huynh-Le MP, Simpson DR, et al. Intensity modulated radiation therapy versus conventional radiation for anal cancer in the Veterans Affairs system. Int J Radiat Oncol Biol Phys 2018;102:109-15.

38. Ramey SJ, Asher D, Kwon D, et al. Delays in definitive cervical cancer treatment: An analysis of disparities and overall survival impact. Gynecol Oncol 2018;149:53-62.

39. Bilimoria KY, Ko CY, Tomlinson JS, et al. Wait times for cancer surgery in the United States: trends and predictors of delays. Ann Surg 2011;253:779-85.

Cite this article as: Mehta S, Ramey SJ, Kwon D, Rich BJ, Ahmed AA, Wolfson A, Yechieli R, Portelance L, Mellon EA. Impact of radiotherapy duration on overall survival in squamous cell carcinoma of the anus. J Gastrointest Oncol 2020;11(2):277-290. doi: 10.21037/jgo.2020.02.09 